\title{
Orthodontic extractions - an investigation of patient management methods
}

\author{
An investigation of patient management methods used for orthodontic extractions by general dental practitioners in \\ North West England A. R. Shepherd and F. J. Hill Br Dent J 2000; 188: 614-616
}

\section{Objective}

To quantify the patient management methods used by dental practitioners for orthodontic extractions and to determine what factors influence their choice of method.

\section{Design}

Practitioners working in the General Dental Service in the area of the former North West Regional Health Authority were randomly sampled and sent a postal questionnaire.

\section{Setting}

General Dental Service in the North West of England.

\section{Subjects}

204 completed questionnaires were returned; a response rate of $71.1 \%$.

\section{Interventions}

Practitioners were asked about the patient management methods that they used for orthodontic extractions and what factors were important in choosing to use a general anaesthetic.

\section{Outcome measures}

The mean percentages of patients treated with local anaesthetic alone, general anaesthesia and inhalation sedation with local anaesthesia were calculated for the sample. Factors influencing the choice of method used were scored by the practitioners on a ten point scale.

\section{Results}

Local anaesthesia alone was used for two thirds of orthodontic extraction patients and general anaesthesia for one third. Inhalation sedation was rarely used. Poor patient cooperation and a nervous patient were the most important factors in choosing a general anaesthetic.

\section{Conclusions}

Local anaesthesia is used for the majority of orthodontic extractions. However there remains an overuse of general anaesthesia and an underuse of inhalation sedation.

\section{In brief \\ - Over two-thirds of orthodontic extractions carried out in the General Dental Service are carried out with local anaesthesia alone. \\ - One-third of orthodontic extractions are carried out under general anaesthesia. \\ - Inhalation sedation is rarely used in the General Dental Service. \\ - The commonest reasons for choosing a general anaesthetic are poor patient co-operation and a nervous patient. \\ - Poor patient co-operation and nervousness are indications for the use of inhalation sedation.}

\section{Comment}

This paper describes the management 1 strategies of a group of general dental practitioners in relation to the choice of anaesthesia for orthodontic extractions in children. Three pain control measures were considered, namely: local anaesthesia alone, local anaesthesia with inhalation sedation, and general anaesthesia. By far the commonest regimen was the use of local anaesthesia. This is encouraging. Inhalation sedation was rarely used by this group of practitioners.

Not surprisingly an important factor in relation to the use of general anaesthesia was the availability of a general anaesthetic service within the practice. The data for this study were collected before the GDC guidelines ${ }^{1}$ relating to the provision of general anaesthesia for dentistry were published. If these recommendations have led to a reduced availability of general anaesthesia in dental practice then it is to be hoped that the use of general anaesthesia for orthodontic extractions in children has decreased since these data were collected.

The authors are surprised that inhalation sedation was rarely used by the practitioners in this study. The authors ${ }^{2}$ and others ${ }^{3}$ have shown that inhalation sedation with local anaesthesia is an effective method of performing extractions and minor oral surgery in children. However it is a timeconsuming approach ${ }^{2}$ and this might affect uptake of this method of pain control in general practice. Whether the use of inhalation sedation and local anaesthesia is preferable to local anaesthesia alone cannot be ascertained from this investigation; some studies have shown that local anaesthesia alone is impressive as a means of pain control for orthodontic extractions, even in patients who were originally referred for general anaesthesia. ${ }^{4}$

\section{J G Meechan}

Senior Lecturer in Oral Surgery, University of Newcastle upon Tyne

1 General Dental Council. Maintaining standards: guidance to dentists on professional and personal conduct. November, 1998.

2 Shepherd A R, Hill F J. Orthodontic extractions: a comparative study of inhalation sedation and general anaesthesia. Br Dent J 2000; 188; 329-331.

3 Shaw A J, Meechan J G, Kilpatrick N M, Welbury R R. Inhalation sedation and local anaesthesia instead of general anaesthesia for extractions and minor oral surgery in children: a prospective study. Int J Paed Dent 1996; 6: 7-11.

4 Tyrer G L. Referrals for dental general anaesthetics - how many really need GA? Br Dent J 1998; 187: 440-443. 